\title{
Digital Storytelling and Key Skills: Problems and Opportunities
}

\author{
Monica Banzato \\ Department of Linguistics and Comparative Cultural Studies, \\ University of Ca' Foscari - Venice, Italy \\ banzato@unive.it
}

\begin{abstract}
This paper presents a pilot study conducted at the University $\mathrm{Ca}$ ' Foscari - Venice, in Italy, in which a group of pre-service secondary school teachers explored the use of digital storytelling through workshops. The aim of this study was to determine the key skills that teachers employ in the production of DS. To this end, the study investigated in detail: the stages of Digital Storytelling (DS) perceived as difficult; the key skills that teachers are able to develop in their use of DS; the obstacles that may prevent the use of DS in schools. Although teachers have recognized the positive value of DS on the pedagogical and educational levels, the sample shows some resistance to using it at school, not so much due to the lack of technical competence, but for institutional reasons such as time constraints, access to technical equipment and curriculum demands.
\end{abstract}

Keywords: Key digital skills, pre-service teachers, digital storytelling, obstacles.

\section{Introduction}

Over the past decade, several studies have shown how the new generations are increasing the hours they spend daily in communicating and sharing digital information, now averaging more than $7 \frac{1}{2}$ hours a day [1]. Their digital practices have kept up with changing fashions: if years ago, students chatted, blogged and downloaded music and video, today they tweet and employ social media apps to share photos, video and artwork on sites like YouTube and Flickr. However, the digital experiences of this generation are not in themselves informative of their critical awareness of being able "to harness human curiosity, the ability to listen, and seek diverse knowledge in the context of integrated information spaces, constant sharing, public identities, and low barriers to production" [2]; or to "personalize content and reorganize it in a fashion that best allows them to make sense of a topic, and to share it with peers" [3].

The school sector has a responsibility to enhance students' formal and informal learning and to ensure their acquisition of digital literacy [4], conceived as the ability to "access content, analyze and evaluate the messages, create presentations, reflect on findings, and work together in collaborative environments" [2]. 
Teachers today are required to be capable of promoting digital literacy and key digital competences [5, 6], including designing authentic learning environments and experiences. In fact, "it is essential to prepare technologically proficient teachers that are able to provide the learning opportunities that facilitate students' use of technology to construct knowledge and to communicate in the networked world we live in" [7].

Digital Storytelling (henceforth DS) is considered one of the educational methods that allows both significant promulgation of digital literacy $[8,9]$ and development of strategic skills for twenty-first century training [10, 11]. "Digital storytelling allows the creation of innovative learning experiences, supported and extended by the application of user contributed content Web 2.0 technologies, empowering teachers' abilities to communicate and integrate technologies into the curriculum" [12].

Seeking to harmonise technological advancements with developments in education, many scholars $[8,13,14,15]$ have suggested that DS represents an ideal combination of technology-integrated learning and social constructivist principles. The social constructivists suggest the importance of students' collaborative learning through using digital tools in educational activities within an authentic environment $[16,17]$, where learners are engaged in constructing and reconstructing their knowledge and beliefs in collaborative ways [18]. In the constructivist learning framework [19, 20, 21, 22], knowledge is not simply transmitted from teacher to student but is actively generated and constructed by the students through social interactions with their physical, social, and technological environment [23, 24]. DS creates an ideal synergy between digital learning environments (i.e. learning management system [LMS], blogs, wiki etc.), technological tools, software (i.e. video editor, audio editor, etc.), and educational objectives (in different subjects, from scientific to humanistic fields) which can facilitate the co-construction of knowledge among students.

However, it is essential to prepare teachers who have completed their pre-service courses and are capable of incorporating their own digital experience in authentic pedagogical pathways. In this manner, teachers should become capable of creating learning opportunities which facilitate the construction and sharing of knowledge with and through multiple channels of information.

Nevertheless, training teachers to employ innovative methods is not a road without obstacles, as beliefs, perceptions, attitudes, experiences and well-established practices, combined with the narrow constraints in which teachers operate (e.g. ministerial programs, organization of schools) can influence positively or negatively the adoption of new ways of learning. This paper aims to answer three basic questions: 1) What are the strengths and weaknesses of DS as perceived by teachers? 2) What are the key skills that teachers would be expected to utilise in DS? 3) What obstacles prevent teachers from employing digital narration in class?

The results presented here are derived from an investigation undertaken at $\mathrm{Ca}$ ' Foscari University, January - May 2013. This research project was undertaken among the participants in a pre-service course, which aimed to instruct teachers in techniques for employing open digital resources and DS. From the 211 participants, 48 teachers of humanities subjects were chosen to participate in a pilot study. As part of the pre- 
service course, a laboratory for the creation of DS was setup, in which the participants shared in the processes of creating and producing finished DS products on the Moodle platform. The completed DS products were utilised to stimulate self-reflection on the methods and professional practices, with the aim of collecting the perceptions of the participants: a) as students, who learn through innovative methods employed in ICT (Information Communication Technology); b) as teachers, who reflect on the key skills that they need to put into practice; c) as reflective practitioners [25], who wish to integrate proven practices with new ones.

The creation of digital stories was also aimed at improving teachers' comprehension and faith in the utility and efficacy of employing ICT in their teaching practices.

\section{$2 \quad$ Digital Storytelling and Key Skills}

There are several definitions of "Digital Storytelling". From a technical point of view, DS can be defined as the task of telling a story through digital media. The product is a short narrated video (amateur, not professional, usually no longer than five minutes) in which there are music, pictures, drawings or videos, and a voice track. The DS can be shared among a small group or among the great community of the internet by such means as posting it on YouTube (or as Open Educational Resources [26, 27, 28]). The creation of a DS requires the development of multiliteracies, the ability to communicate fluently through traditional and new media, as well as the ability to access, analyze and evaluate the huge amount of network information to create an individual video that weaves, in an original and personal manner, narrative text and vocalisation, images, and sounds. DS can be used in educational activities at all grade levels, up to tertiary education and beyond.

According to Lambert [29], DS should be defined by the presence of seven elements: 1. Point of View: the author begins with his own point of view; 2. A Dramatic Question: the author poses a question (or a problem) which will be answered by the end of the work; 3. Emotional Content: the author gives emotional force to the initial question in order to highlight the problem he/she is addressing; 4. The Gift of your Voice: the author tells the story in his own voice, in order to personalize the work and to help the listener understand the narrative; 5 . The Power of the Soundtrack: the author selects music or other sound effects in support of the plot; 6. Economy: the author designs a brief narrative. Facts must be used to give flavour to the story, not to overwhelm the viewer with excess information; 7. Pacing: the author decides on the pace of the story (slow or fast).

DS can be employed for various purposes: to inform, to demonstrate or to communicate a personal vision. "The topics that are used in Digital Storytelling range from personal tales to the recounting of historical events, from exploring life in one's own community to the search for life in other corners of the universe, and literally, everything in between" [8]. It can be used in several ways: it could be created by teachers as a media resource to present an argument and form the subject of classroom debate, or it might be created by the students themselves, individually or in 
groups. "DS puts technology in the students' hands and stimulates research skills and creativity" [12].

According to Porter [30], "For students to be effective communicators in the $21 \mathrm{st}$ century, they need to be sophisticated in expressing ideas with multiple communication technologies, not just the written word". Digital Storytelling is an application of educational technology which uses almost all of the skills that students are expected to have in the 21st century [31]. This proposition is affirmed by Robin, who states [8]: "This creative work provides students with a strong foundation in what many educators have begun calling 21st century Literacy, Digital Age Literacy or 21st Century Skills". According to Robin [8], DS develops four key skills: "Digital literacy: the ability to communicate with an ever-expanding community to discuss issues, gather information, and seek help; Global literacy: the capacity to read, interpret, respond, and contextualize messages from a global perspective; Technology literacy: the ability to use computers and other technology to improve learning, productivity, and performance; Visual literacy: the ability to understand, produce, and communicate through visual images; Information literacy: the ability to find, evaluate, and synthesize information".

\section{$3 \quad$ Pre-service Teachers and Digital Storytelling}

A review of the literature reveals an increasing interest regarding the use of DS in the initial training of teachers. For example, Yerrick et al. [32] analyse the use of digital video editing as a significant method to encourage meaningful reflection on the part of teachers. Their research focuses on the impact of DS on the beliefs of pre-service teachers, concentrating, in particular, on teachers' understanding of children's thinking and their own teaching experience. Barrett $[33,34]$ argues that the use of DS by teachers "is a highly motivating strategy that allows them to make concrete and visible observations about their own practices". His research has investigated the convergence of "student engagement, reflection for deep learning, project-based learning and the adductive integration of technology into instruction". Tendero [35] examines the use of digital storytelling as a means by which teachers have the opportunity to develop multiple points of view for the analysis of their own beliefs. Li [36] conducted an exploratory research project on the usefulness of the use of DS to build an e-portfolio, by means of reflection and self-assessment of the learning process. The researcher found "a useful tool in the enhancement of teaching and learning new literacies in today's technology enriched environments". Heo [37] examined the effects of the experience of DS in pre-service in terms of "teachers' self-efficacy towards educational technology". In addition, this study examined the professional arrangements of the teachers involved, including the opening of a shift to technology education, the degree of availability in the development of educational technologies and the willingness to work beyond the contractual hours of work for the integration of technology into teaching practices at school. Dogan and Robin [38] examined the educational impact and obstacles of DS in the classroom, among a group of pre-service trained teachers. Kearney [39] examined the potential role of DS 
in pre-service training, focussing on teachers' construction of e-portfolios. He also investigated digital storytelling as "a support for self-reflection during teacher training". Kearney [39] noted that "digital stories can help address the problem of reflection being perceived by students as over-used and that students can use new media to initiate reflective processes in compelling ways". He affirms that further research should be conducted on the use of DS in pre-service, which he defines as "a crucial but underdeveloped area of research into teacher learning".

\section{$4 \quad$ Background and Research Methodology}

The pilot study took the approach of case studies, collecting and processing qualitative and quantitative data. The information, collected through two questionnaires, interviews and digital storytelling produced by the pre-service teachers in the workshop, is set out below:

1) The first questionnaire, used at the beginning of the laboratory, allowed the gathering of data on computer skills, the use of video and narrative methods in teaching practice.

2) The second questionnaire, which was used at the end of the workshop, allowed the collecting of information on the strengths and weaknesses of DS as perceived by teachers from two different perspectives: a) as a student, the stages of DS perceived to be difficult; b) as a teacher, the key skills that teachers were able to implement/develop in their DS projects; c) in general, what obstacles might prevent the use of DS in classrooms.

3) The interviews, conducted to triangulate the survey data 1 and 2 , were carried out in oral form, throughout the laboratory, and transcribed at the end of the laboratory. The interviews provided further, accurate information on issues that surveys 1 and 2 could not investigate. This work allowed the identification of a sufficient number of significant interviews (about $80 \%$ of the participants in the laboratory).

4) DS video products were also useful for the collection of data on key competences of teachers and the educational use of DS.

Given that digital storytelling is a relatively new teaching method in the Italian context and that there are no available data, this study provides information on the attitudes of humanities teachers: (1) regarding the use of basic technology by those with experience of DS methods; (2) on key skills that this sample of in-service teachers are able to implement with DS; and (3) obstacles that may prevent the use of innovative methods and technologies in schools.

The limitations of this study are: a) the sample size (48 participants), although representative, only covers one sector of higher education, humanities (the sciences are absent); b) the sample comes mainly from the north-east of Italy and therefore covers a limited portion of the country; c) the short time frame in which the study took place (five months) limited observations to the period of the workshop and it has not been possible to verify de facto the impact of the data collected. In fact, although 
a portion of the sample was contacted six months after the end of the workshop, the number of respondents was not enough to form a significant sample.

\section{$5 \quad$ Results}

\subsection{Sample of Teachers}

The study was conducted on a sample of 48 humanities teachers, of which $60 \%$ (28) were females and $40 \%$ (19) were male. A total of $77 \%$ (37) of the sample declared an average experience in secondary schools of 4.7 years for females and 3.8 years for males, an average of 4.2 years. Only $22 \%$ (11) declared themselves new graduates without significant teaching experience.

\subsection{Survey Results 1}

The first questionnaire was distributed at the beginning of the workshop and had the following objectives: (a) to collect data on the computer skills needed to create a video (in particular, the use of Audacity and MovieMaker or another software editor for audio and video); (b) to explore whether teachers had previously employed narrative methods in their teaching practices in the classroom, not necessarily related to the use of technology; c) to determine whether the sample had previously used video in class.

Regarding (a) their knowledge of the software, 95\% (46) of the sample declared that they had never used Audacity (though 70\% - 34 - claimed to know other software for audio recording), while 45\% (22) claimed to have used MovieMaker, 4\% (2) iMovie (Apple), and 2\% (1) other editing software (Adobe Premiere, Final Cut).

In response to the question (b), if they had already used narrative practices in teaching, $77 \%$ (37) of the participants said they had not specifically used narrative methods in the classroom before the workshop on DS. Based on interviews conducted on the sample, it appears that there is broad interest in narrative methods, especially after knowing DS and having enjoyed this opportunity.

The question (c) about using videos in the classroom produced the following results: $87 \%$ (42) replied, "I have used videos produced by others"; $6 \%$ (3) said, "I have created digital video"; no teacher selected the answers, "I edited videos produced by others", "I created videos with colleagues" (collaboratively constructed video), or "I assigned my students to create a video as a task".

From this preliminary analysis, it appears that the use of video is present in the teaching practices of this sample, together with other materials. However, it appears that the members of this sample did not have digital experiences of creating, editing and sharing video ("user generated content"). Furthermore, narrative methods (whether digital or otherwise) do not seem to be widespread in this sample. Finally, the analysis of the sample data does not reveal previous experience of digital storytelling or of other educational activities that merge the narration with multimedia languages (such as video) and sharing them on the internet. 


\subsection{Survey Results 2}

The second survey was conducted at the end of the workshop, after the teachers had experienced all the stages of DS and finished their video. This phase of the survey was aimed at gathering information to identify:

a) the stages of DS perceived as difficult;

b) the key skills that teachers are able to develop in their DS project;

c) the barriers that may prevent use of DS in the classroom.

\subsubsection{Perceptions of Teachers on Educational and Technical Phases of DS}

Despite the fact that satisfaction about DS was a high 4.6 on a $0-5$ scale and that very positive comments were made by the participants in the interviews, teachers reported some difficulties during the development of DS.

The main difficulties at the technical level are represented by the voice-audio recording $(81 \%, 39)$ and video editing $(90 \%, 43)$. From the interviews it emerged that the Audacity software is considered to be a good product, compared to other open software, although slightly more complex.

Reported difficulties were not related to use but in determining the right location to record the voice (i.e. to have audio narration of high quality and loud enough to be heard clearly) or hardware-related (lack of a good microphone or sound card) and also the ability to make meaningful the use of their voice (prosody, intonation, etc.). In this case, the teachers felt it would be interesting to promote a workshop on "reading aloud" or "theatre", in order to make the reading similar to expressive acting.

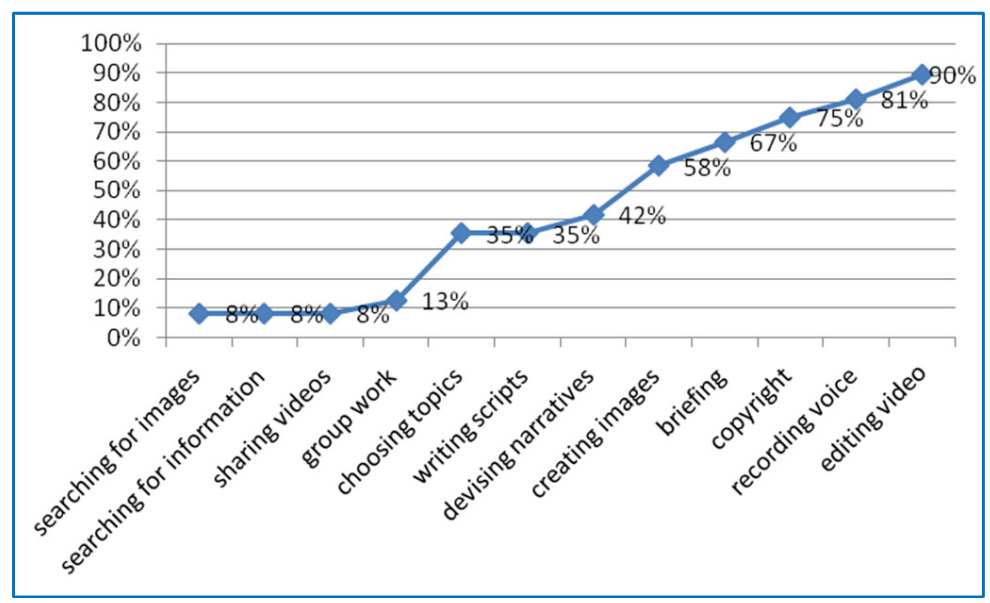

Fig. 1. Stages of DS considered the most critical are those with higher rates

The video editing was an issue for the majority of the sample $(90 \%, 43)$. From a technical point of view, teachers complained that MovieMaker is not stable software: at times, it suddenly stops working and, as a result, the video editing can be lost. Video editing was perceived by teachers to be interesting, but the synchronization of 
audio-voice, audio-music, subtitles, video and images requires a lot of time, and the results are not always satisfactory.

Work groups were considered a strength in creating DS and the majority of the participants preferred to work in this mode (only 2 people, out of 48 , chose to work individually). However, teachers identified other difficulties, such as: the phase of the initial briefing $(67 \%, 32)$ was costly in terms of time, since the participants had to know each other and decide how to organize and manage the various stages of the work. The conception of storytelling $(42 \%, 20)$ and the choice of topics $(35 \%, 17)$ also took time, but these moments were regarded positively as creative and stimulating learning. However the "rendering of words into images, or images into words" required long reflection.

The phase of researching images and videos was much appreciated by teachers, while the creation of the images was difficult for $58 \%$ (28) of the sample. This is due to two reasons: (a) some participants believed that they did not have sufficient skills with photography and video; and (b) they considered that they had not had enough experience translating "words into images" and "images into words". During the interviews, it was possible to capture another critical aspect, which is the copyright of some images $(75 \%, 36)$, the teachers often had to find ways to avoid violating copyrights (DS requires that sources from which information is derived, whether text or images, be cited). The sharing of video products in the Moodle platform was much appreciated, because the teachers could examine the videos of other colleagues (who provided new ideas and solutions for their own work) and discuss educational issues in the forum. However, only one group decided to publish its products on YouTube. For some teachers, the process of writing was critical $(35 \%, 17)$, for two reasons: (a) some teachers indicated that they preferred description and explanation of topics rather than narration; (b) others noted that DS requires that scripts be written very concisely.

\subsubsection{Key Skills for Teachers}

Teachers were asked: "what are the key skills that your DS project develops in students?" At the beginning of the course, when DS was introduced, the teachers were presented with a list of 12 competencies developed by the American National Standards, NETS-S, and 21st Century Skills [9]. To this list were added three more digital skills related to the production of user-generated content that are well suited to video DS (sharing videos, creating community, using Creative Commons). Here follows a summary of a brief description of the key competencies.

“1. Cognitive Apprenticeship: practicing real-world work of digital communication;

2. Creativity and Inventive Thinking: creating multi-sensory experiences for others;

3. Higher Order Thinking Skills (HOTS): going beyond existing information to add personal meaning and understanding;

4. Enduring Understanding: by telling the story of what you know and understand for others, authors deepen their own self-meaning of the topic;

5. Visual Literacy: using images to show, not tell, the narrative story; 
6. Technical Literacy: mastering the craftsmanship of applying the technology tools to create powerful communication, not to just use the tools, but to mix and dance the media into illuminated understandings;

7. Information (Media) Literacy: thinking, reading, writing, and designing effective media information;

8. Effective Communication: reading and writing information beyond words;

9. Multiple Intelligences and Learning Styles: addressing not only the opportunity for students to use their preferred mode of learning and thinking, but also enabling them to practice the effective use of all modalities;

10. Teaming and Collaboration: growing skills through practiced opportunities to co-produce group projects;

11. Project Management Mentality: challenge for students to practice time management of complex, involved tasks to successfully meet deadlines modelling real-world tasks;

12. Exploring Affinity: when students create meaningful, engaged work, they discover themselves as successful learners" [9].

13. Community: Use DS to create a learning community;

14. Sharing: share DS with the class, the school and wider community;

15. Using Creative Commons: respect the copyright and the resources utilised.

To answer this item of the questionnaire, teachers had to attribute scores to each of the 15 competencies presented (Very Important, Important, Some Importance, No Importance) according to the degree of importance they attributed to creation of DS by participants. Figure 2 shows the results.

The skills considered "very important" were: 2 . Creativity and Inventive Thinking, selected by $69 \%$ (33) of the sample; 3 . HOTS, $85 \%$ (41); 4. Enduring Understanding, $89 \%$ (43); 7. Media and Information literacy, 90\%; 8. Effective Communication, 95\% (46); 10. Teaming and Collaboration, 95\% (46); 12. Exploring Affinity, 77\% (37); 15. Use Creative Commons, 95\% (46).

The skills considered "important", but not fully exploited in their DS projects, were: 1. Cognitive Apprenticeship, 48\% (23); 5.Visual literacy, 66\% (32); 6. Technical Literacy, 33\% (16); 12. Sharing videos, 77\% (37); 13. Community, $85 \%$ (41).

From the interviews, it appears that skill 1. Cognitive Apprenticeship, did not receive much attention because the participants were mainly focused on curricular issues, topics covered by ministerial programs (i.e. poems, prose, novels, writers, etc.) or topical issues (such as racism, drugs, autobiographies, etc.).

In the end, most of the projects designed by the teachers' DS did not provide links to organizations outside school. Competence 5. Visual Literacy is considered important, but teachers feel they do not have the visual skills, which could instead be developed by colleagues who teach art (most of the sample were teachers who teach Italian literature). Competence 6. Technical Literacy is considered important, but nevertheless the software used for DS is considered basic and therefore it is not thought that DS is technically difficult. The majority of teachers prefer to share the 
student video with the class or with the school, but they prefer not to publish their videos on the internet (12. Sharing videos).

The interviews show the following concerns: when teaching underage students, teachers have to face a heavy bureaucratic practice to get the necessary permits and this becomes expensive in terms of time and commitment. This is linked to competence 13. Create Community, which was intended as a class and/or school community, not the wider territorial community or the internet community.

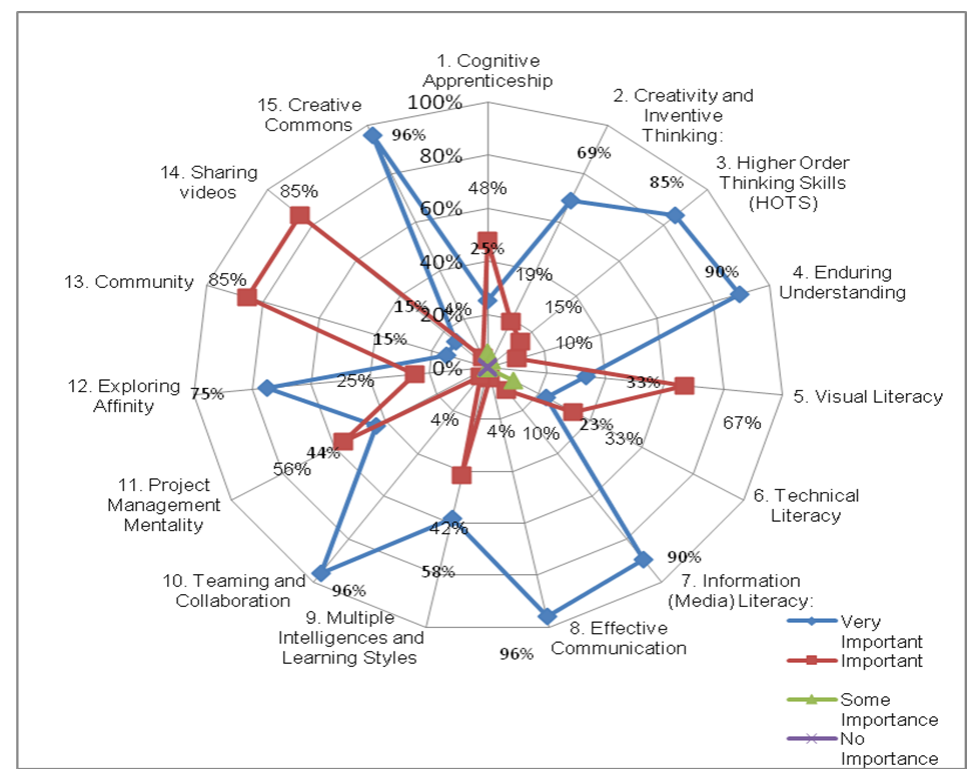

Fig. 2. Stages of DS considered the most critical are those with higher rates

\subsubsection{Obstacles to Teachers' Use of DS}

Participants were asked what obstacles might hinder the use of DS in their classrooms. Their responses were divided into three categories - "issues of time", "issues of curriculum" and "access to the technologies" - which had been identified as the major obstacles to the use of DS in schools by $95 \%$ (46) of respondents.

The interviews showed that teachers complain of having only a few hours a week in order to develop DS. In addition, they were concerned about having to carry out the topics required by ministerial programs (curriculum) to deadlines that the timeconsuming development of DS might interfere with. The situation is also complicated by the difficulty of access to computer laboratories. This sample stated that in the schools there is only one classroom with computers, but it must serve all classes. For this reason, teachers need to book the computer laboratory, consistent with the needs of other colleagues, and its availability is not always sufficient for the needs of their educational activities. From the teachers' responses it appears that the hardware and software are often not up-to-date and the technical staff is not always available to solve technical problems. Here are some typical participants' answers: 
Interviewee \#13 stated: "The critical points are the few hours that we have in high school for teaching. This makes it difficult to devote myself entirely to DS; very often schools do not have up-to-date computer labs and this fact is not of secondary importance; finally, the absence of technical staff discourages the tackling of digital work".

Interviewee \#8 stated: "The critical issues are related to the time required for a DS project. The ideal would be to propose it as an extracurricular activity, given the limited time in the morning devoted to school. Knowledge of how to use software needed for DS is not guaranteed: it would therefore be useful to have a course specifically for teachers and students. The computer labs are a critical point: they are not always available and the hardware is not quite up to date".

Interviewee \#43 stated: "Among the most problematic situations in the context of the tradition of Italian public secondary schools is probably linked to the spread of multimedia technologies. The difficulty of making a DS video lies mainly within the limits of available hours for my subject (written and oral tests, programming to complete and large classes). There is insufficient time leftover to teach and employ video and audio editing programs".

\section{Discussion and Conclusion}

The results show that this sample of teachers is in a phase of transition from traditional literacy to digital literacy. There are still many obstacles to overcome which seem less dependent on resistance by teachers but more linked to external constraints (lack of time, ministerial programs, access to technology), as highlighted in the previous section (5.3.3). The results reveal that:

(a) Pre-service teachers show openness and curiosity for innovative methods such as DS. They demonstrate a good familiarity with the technology, although they have only moderate confidence in the integration of the production of DS video in teaching, even if narrative is considered to be a very interesting and productive methodology.

(b) Although these teachers appear familiar with the basic digital technologies, from their answers it emerges that they are resistant to the more advanced practices of web 2.0, such as creating, participating in, and sharing videos on social networks (i.e. YouTube, Vimeo, etc.). The sample appears more inclined to share videos in a protected environment, such as a class group or school. It seems that this choice is due not so much to lack of confidence in the practice of web 2.0, but the perceived need to avoid the bureaucracy required for publication of materials produced by minors on the internet.

(c) This result is also reflected in the selection of the key competences considered important by teachers in their DS projects. It emerges from the interviews that this sample is aware of the potential of DS for the developing of a set of key competencies for digital literacy in teaching and learning. However, if some key competencies are selected above others, this is due less to diffidence or lack of digital skills in the practices of creating and sharing of materials, but results 
from deliberate choices to avoid logistical or bureaucratic problems of (e.g. authorizations for minors, access to technology) or for reasons of time.

(d) This result is confirmed in the last questionnaire, which investigates what are the obstacles that prevent the use of DS in the classroom. The responses concentrate with great intensity on logistical problems (such as lack of equipment, obsolete computers or insufficient numbers of computer laboratories, as well as hardware and software problems and lack of technical support). They also cite the lack of available time (some stages of DS take a long time to be realized, such as group work, sharing, audio recording, video editing) and the limits due to ministerial programs (i.e. teachers, while recognizing the validity of the method, are under pressure to finish the annual program on time). DS also encounters bureaucratic obstacles, such as requests for permission to publish student work on the internet or to conclude agreements with institutions outside the school or community if the videos are to be open for viewing by the outside world. The interviews reveal that one solution might be for DS to be developed outside of the curriculum hours; however, if DS is used in curricular hours, its structure should be simplified or reduced. Teachers would need the support of school administrators, where these types of activities are encouraged and facilitated.

Finally, in Italy, we would need to profoundly revise the current curriculum of the secondary schools, which is still too rigid to apply learning processes that arise from the nature of digital work, as well as continue to provide substantial support for the training of teachers, and enable them to have enough time to explore the potential of digital storytelling and its uses in the classroom. In fact, the workshop on DS at the university was not without its difficulties: given the high number of teachers who attended the course and the few hours granted to realize their DS projects in the laboratory. However, the collaborative approach of the participants led to positive results and has allowed the realization of this pilot study on the potential of DS in learning.

\section{References}

1. Kaiser Family Foundation: Generation M2: Media in the lives of 8-18 year-olds. Henry J. Kaiser Family Foundation, Menlo Park, CA (2010)

2. Hobbs, R.: Digital and Media Literacy: Connecting Culture and Classroom. Corwin Press, Thousand Oaks (2011)

3. Lessig, L.: Remix: Making Art and Commerce Thrive in the Hybrid Economy. Penguin, New York (2008)

4. Mihailidis, P., Cohen, J.: Exploring Curation as a core competency in digital and media literacy education. Journal of Interactive Media in Education (2013), http://wwwjime.open.ac.uk/jime/article/viewArticle/2013-02/html (retrieved February 16, 2014)

5. Gilster, P.: Digital Literacy. Wiley Computer Publishing, New York (1997)

6. Buckingham, D.: Media Education: Literacy, Learning and Contemporary Culture. Polity Press-Blackwell Publishing, Cambridge (2003) 
7. Coutinho, C.P.: Web 2.0 tools in pre-service teacher education programs: An example from Portugal. In: Remenyi, D. (ed.) The Proceedings of the 7th European Conference on e-Learning, pp. 239-245. Academic Publishing Limited, Reading (2008)

8. Robin, B.R.: Digital Storytelling: A Powerful Technology Tool for the 21st Century Classroom. Theory Into Practice 47(3), 220-228 (2008)

9. NETS-T: The ISTE- International Society for Technology in Education, 2008 Report (2008),

http: / / www . iste.org/Content/NavigationMenu/NETS / ForTeachers / 2008Standards/NETS_T_Standards_Final.pdf (retrieved February 16, 2014)

10. European Commission: Communication from the Commission to the European Parliament: The Digital Agenda for Europe - Driving European growth digitally. Brussels, 18/12/2012, $\operatorname{COM}(2012 b) 784$ (2012). Commission of the European Communities, Brussels, Belgium (2012)

11. European Commission: Europa 2020 una strategia per una crescita intelligente, sostenibile e inclusiva. Commission of the European Communities, Brussels, Belgium (2010)

12. Coutinho, C.P.: Storytelling as a Strategy for Integrating Technologies into the Curriculum: An Empirical Study with Post-Graduate Teachers. In: Maddux, C.D., Ginson, D., Dodge, B. (eds.) Research Highlights in Technology and Teacher Education 2010, pp. 87-97. Society for Information Technology and Teacher Education (SITE), Chesapeake (2010)

13. Sadik, A.: Digital Storytelling: A meaningful technology-integrated approach for engaged student learning. Educational Technology Research and Development 56(4), 487-506 (2008)

14. Di Blas, N., Paolini, P., Sabiescu, A.: Collective digital storytelling at school as a wholeclass interaction. In: Proceedings of IDC 2010, New York, NY (2010)

15. Yang, Y.-T.C., Wu, W.-C.I.: Digital storytelling for enhancing student academic achievement, critical thinking, and learning motivation: A year-long experimental study. Computers \& Education 59(2), 339-352 (2012)

16. Koohang, A., Riley, L., Smith, T., Schreurs, J.: E-Learning and Constructivism: From Theory to Application. Interdisciplinary Journal of E-Learning \& Learning Objects 5(1), 91-109 (2009)

17. Neo, M., Neo, T.K.: Students' Perceptions In Developing A Multimedia Project Within A Constructivist Learning Environment: A Malaysian Experience. TOJET: The Turkish Online Journal of Educational Technology 9(1), 176-184 (2010)

18. Vygotsky, L.S.: Mind in society: The development of higher psychological processes. Harvard University Press, Cambridge (1978)

19. Kanuka, H., Anderson, T.: Using constructivism in technology-mediated learning: Constructing order out of the chaos in the literature. Radical Pedagogy 1(2) (1999), http: //www.radicalpedagogy.org/Radical_Pedagogy/Using_Constr uctivism_in_Technology-

Mediated_Learning_Constructing_order_out_of_the_Chaos_in_th e_Literature.html (retrieved February 16, 2014)

20. Tam, M.: Constructivism, instructional design, and technology: Implications for transforming distance learning. Educational Technology \& Society 3(2), 50-60 (2000)

21. Jonassen, D.H., Carr, C.S.: Mindtools: Affording multiple knowledge representations for learning. In: Lajoie, S.P. (ed.) Computers as Cognitive Tools, vol. 2, pp. 165-196. Lawrence Erlbaum Associates, Mahwah (2000)

22. Wheatley, G.H.: Constructivist perspectives on science and mathematics learning. Science Education 75(1), 9-21 (1991)

23. Fosnot, C.T.: Constructivism: A psychological theory of learning. In: Fosnot, C.T. (ed.) Constructivism: Theory, Perspectives, and Practice, pp. 8-33. Teachers College Press, New York (1996) 
24. Prawat, R.S.: Constructivisms, modern and postmodern. Educational Psychologist 31(3/4), 215-225 (1996)

25. Schön, D.: The reflective practitioner: How professionals think in action. Basic Books, New York (1983)

26. OECD: Giving knowledge for free: The emergence of Open Educational Resources. OECD, Paris, France (2007)

27. UNESCO: 2012 Paris OER Declaration. 2012 World Open Educational Resources (OER) Congress. Unesco, Paris, (2012)

28. Banzato, M.: Barriers to teacher educators seeking, creating and sharing open educational resources: An empirical study of the use of OER in education in Italy. In: 15th International Conference on Interactive Collaborative Learning, ICL (2012), doi:10.1109/ICL.2012.6402105

29. Lambert, J.: Digital Storytelling: Capturing Lives, Creating Community, 3rd edn. Digital Diner Press, Berkeley (2009)

30. Porter, B.: DigiTales: The Art of Telling Digital Stories. DigiTales StoryKeepers, Sedalia (2004)

31. Jakes, D.: Standards-proof your digital storytelling efforts. TechLearning (2006), http: / /www. techlearning.com/story/showArticle.jhtml?articleI $\mathrm{D}=180204072$ (retrieved February 16, 2014)

32. Yerrick, R., Ross, D., Molebash, P.: Too Close for Comfort: Real-Time Science Teaching Reflections via Digital Video Editing. Journal of Science Teacher Education 16(4), 351375 (2005)

33. Barrett, H.: Storytelling in Higher Education: a Theory of Reflection on Practice to support Deep Learning. In: Society for Information Technology and Teacher Education International Conference 2005, pp. 1878-1883. Association for the Advancement of Computing in Education, Charlottesville (2005)

34. Barrett, H.: Digital Stories in ePortfolios: Multiple Purposes and Tools (2006), http://electronicportfolios.org/digistory/purposes.html (retrieved February 16, 2014)

35. Tendero, A.: Facing Your Selves: The Effects of Digital Storytelling on Teacher Education. Contemporary Issues in Technology and Teacher Education 6(2), 174-194 (2006)

36. Li, L.: Digital Storytelling: Self-Efficacy and Digital Literacy. In: Reeves, T., Yamashita, S. (eds.) Proceedings of World Conference on E-Learning in Corporate, pp. 2159-2164. AACE, Chesapeake (2006)

37. Heo, M.: Digital Storytelling: An empirical study of the impact of digital storytelling on pre-service teachers' self-efficacy and dispositions towards educational technology. Journal of Educational Multimedia and Hypermedia 18(4), 405-428 (2009)

38. Dogan, B., Robin, B.R.: Implementation of Digital Storytelling in the Classroom by Teachers Trained in a Digital Storytelling Workshop. In: McFerrin, K., Weber, R., Carlsen, R., Willis, D.A. (eds.) Proceedings of Society for Information Technology \& Teacher Education International Conference 2008, pp. 902-907. AACE, Chesapeake (2008)

39. Kearney, M.: Investigating Digital Storytelling and Portfolios in Teacher Education. In: World Conference on Educational Multimedia. Hypermedia and Telecommunications, Honolulu, HI (2009) 